\title{
Sound Patterns as Connectors: An Experimental Production of Three Sisters
}

The actor is tasked with embodying text in order to portray the characters' intentions.

This article shows that such a complex task escalates when the actor performs in a second language. In South Africa, where eleven official languages are embraced, the multiplicity and crossover of spoken languages is a daily challenge for actors and theatre makers, leading to a preference for physical performances, which limits the use of text. The production of embodied sound patterns embedded in a text informed the creative process of an experimental production of Chekhov's Three Sisters. It was created with a second-language cast (speakers of Setswana and Afrikaans) whose over-arching goal was to consider the embodied patterns of pre-linguistic expression as a theatre-making tool. When reflecting on their work, the actors indicated that their explorations facilitated a connection with the text in English and generated the relevant dynamics for the play's sociopolitical themes to be adequately 'translated' to a contemporary multilingual South African context. Karina Lemmer is a Senior Lecturer in the Department of Performing Arts at Tshwane University of Technology in Gauteng, where she teaches acting and voice. She has directed a number of multilingual productions, including Buried Voices (2018) and Motlotlegi (2019), and has published in the Voice and Speech Review (2018).

Keywords: embodied text, second-language performance, prosody, physicality, drawing.

THIS ARTICLE reflects on an experimental multilingual production of Chekhov's Three Sisters performed at the University of Pretoria (October 2017), the POPArt Theatre in Johannesburg (May 2018), and the SA State Theatre (August 2018) during the Vavasati International Women's Festival. It describes the focused explorations that were central to the creative process in a logbook format documenting specific strategies used to empower actors tasked with embodying text in a second language.

Three Sisters is the outcome of a study concerned with second-language actors within the South African context, where eleven official languages are used. Such linguistic multiplicity means that actors are often confronted with embodying characters in a language that is not their first. Although there are several approaches towards embodying text in contemporary acting, the multilingual actor receives limited attention. The explorations here described were intended to enable the embodiment of a second-language text not at a lexical level but by unlocking the sound patterns or prosody established by variations in pitch, duration and intensity, which are present in all human beings at a pre-linguistic level. An unlocking approach of this kind removes the notion of 'correctness', enabling the actor to connect with the emotional patterns embedded in a text.

When working in a multilingual context, an actor often requires help with the secondlanguage text when the text as such gets in the way of performance. Because experimental attempts at resolving difficulties are profoundly situational, it is not always clear what role they play in assisting the actor's performance. Furthermore, since such attempts are woven into the rehearsal process, they subsequently raise the question of whether they actually had assisted the actor. In the experiment discussed here, we wished to determine whether our exploratory approach really did help the actor to convey the character's motives in a second language. An open view was necessary, since my subjective experience and understanding could be significantly 
different from those of any given actor. I also wanted to investigate what the outcome would be if I relied on the same processes of trying and testing to guide my directing.

\section{Selecting the Text and Cast, and Organizing Rehearsals}

Since the focus of our exploratory work was prosody as a creative tool for the secondlanguage actor and the overall creative process, I decided to use a text in which the action is in the dialogue. In Anton Chekhov's plays, action, character, theme, and plot are driven by direct and indirect discourse. ${ }^{1}$ All action is driven by dialogue because many pivotal dramatic moments occur offstage. ${ }^{2}$ Conversation is a driver of action, given that Chekhov's characters frequently do not say what they mean; they may be talking about the weather, but their mundane talk may well hold a deeply emotional, layered subtext. ${ }^{3}$ And it is precisely this that makes a play by Chekhov an effective choice for exploring prosody: pitch, intensity, and duration pertaining to the spoken word allow an actor to move dramatic action forward through the inner substance of the words that are spoken. Chekhov's drama reflects the western text-based theatre tradition, which contrasts with the African paradigm where storytelling and physicality are central to theatrical performance. ${ }^{4}$ Chekhov's plays are thus symptomatic of the type of text that second-language-speaking South African actors find challenging to engage with.

Chekhov's is a complex work featuring ten characters, and it is thematically dense. Our adaptation focused on the inner and outer conflict of the three central female characters and, as a result, the other characters were removed, enabling the cast and director to home in on Chekhov's thematic elements, which are still relevant to women's lives over a century after the work was first performed in Russia in 1901. Universal themes such as love, marriage, ageing, and ambition appear strongly in the work.

Within our contemporary South African context, society and class are phenomena that have had a lingering impact on the historical inequalities still evident today. Chekhov's play considers individual experience within the context of systemic inequality, and comments on those who isolate themselves from other social groups. These are elements that should be problematized in regard to contemporary South Africa. The sisters experience dissatisfaction as outer circumstances and the influences of patriarchy generate inner conflict. We also selected Three Sisters because it features complex female characters suitable for an all-female cast. We found that prosody, specifically when expressing emotion, related to gender. ${ }^{5}$ We thought, then, that an allfemale cast would remove a potential variable within the creative experiment and our subsequent reflections on it.

A certain degree of homogeneity had to be established since second-language speakers of English are likely to display transfer from their first language in their speech melody. ${ }^{6}$ It was therefore important to select actors who shared a first language. In an effort not to limit the exploration to one first-language group, it was decided to use two casts, each consisting of three actors. Consequently, three actors who speak Afrikaans as their first language, and three who use Sesotho and Setswana, or a combination of Sesotho and Setswana, as their first language were invited to participate. ${ }^{7}$

Our overarching goal was to explore creatively the prosodic delivery of a second-language text and to let this shape the actors' and director's processes and the performance outcome. Prosody is complex and intertwined as it influences, and is influenced by, various aspects of the communicative act, which includes social ritual, paralinguistic and nonverbal expression, age, gender, culture, power, and affective or emotive expression. ${ }^{8}$ It is also a competence that is acquired and applied unconsciously. Thus we thought it important to allow free creative exploration rather than conscious application of 'method', and we decided to employ a semi-structured process rather than work within a preconceived and planned structure. And so an 'after the fact' approach was used in which explorations informed the creative process while the latter was reflected upon by the cast and director. Even so, our free process did involve some aspects that were planned in advance 
such as our adaptation of Chekhov's text and our review of relevant literature.

Specific references within the text were removed and the text was condensed into four pivotal scenes that featured conversation between the three sisters. Our first scene was the play's opening conversation concerning Irina's birthday and the sisters' longing for times past. In the second scene the conversation escalated as they expressed dissatisfaction with their lives, relationships, and career prospects; and the sisters discussed their brother, who had mortgaged their family home. In the third scene the sisters, having lost their family home, contemplate their mortality and sense of loss. Finally, we used a short conversation in which the sisters discuss donating clothes to the poor who have lost their homes. ${ }^{9}$

Adapting the text to centre on four scenes was deliberate because it allowed for different explorations of each scene during the initial phase, allowing reflection on how it was performed. Thematically speaking, conversations were selected that gave us the scope to speak of privilege and exclusivity, which are widely considered in South Africa to relate to the country's contemporary postcolonial situation. ${ }^{10}$

The rehearsal process focused on prosody activated through gesture, music, drawing, and words. I purposefully did not plan any of the time and space aspects integral to directing, and the actors only received the script on the day when rehearsals began. This means that the entire process evolved around prosody-centred explorations going towards the performed production. Thus it was simultaneously an exploration and a rehearsal process in four phases. In the first phase the two casts explored the text separately to enable independent discovery of the unique linguistic qualities demanded by some of our attempts. Such a division ensured that the cast members used their first language spontaneously when exploring the first three scenes. During the second phase, the experiences of both casts were combined and elements were revisited to generate a performance. All the scenes explored were included in this second phase, as was the final short fourth scene.
Phase 3 saw intensive rehearsals material accrued for what could be called the final preparations for the performance. This phase involved technical aspects such as sound and lighting elements; I continued my daily journal. The final phase was after the performance, and it included an unstructured reflective discussion with each actor in which they thought about and commented on the creative process as a whole.

Discussions in the form of unstructured recorded conversations were conducted throughout. When embodying the character, the actor harnessed everything that she had felt, thought, seen, and done to create the character's thoughts and feelings. This entailed an interplay between the objective demands of a role and the subjective motives of the actor portraying the role. ${ }^{11}$ Prosody is a pre-linguistic intuitive act of expression that conveys emotional intent. ${ }^{12}$ Consequently, these activities are intuitive by definition, and it was considered most valuable to allow each actor to express her unique experience verbally. My director's journal indicated how the explorations continually informed the directing process.

\section{Reflections on Exploring Gesture in Scene I}

For the purpose of this article, each cast member is assigned a code. The Afrikaans firstlanguage cast is coded as $\mathrm{A}_{1}, \mathrm{~A}_{2}, \mathrm{~A}_{3}$, and A4. ${ }^{13}$ The Sesotho/Setswana cast is coded as $S_{1}, S_{2}$, and $S_{3}$. Cast members' experiences of a specific exploration are quoted in their own words, as recorded in the reflective discussions. Selected comments from the actors are included to illustrate outcomes. An audio recording of the final performance was used to generate samples of the actor's text delivery and it is used here to investigate how prosody operated in specific scenes.

The pre-linguistic, first prosodic patterns of the infant babbling phase are connected to non-verbal expression that includes gesture, facial expression and gaze. ${ }^{14}$ This is sustained as linguistic development unfolds, with gesture remaining a complementary co-expresser to speech. ${ }^{15}$ The complementary interplay between speech and gesture suggests 
body-mind connectivity as meaning is made and expressed through speech. Phillip B. Zarrilli describes this as the subtle dimensions of the body and mind working together in the moment to connect speech-thought, non-verbal communication, empathy, and emotion, ${ }^{16}$ Rick Kemp calls such connected acting 'embodied acting'. ${ }^{17}$ The pre-linguistic connection between gesture and prosody led to the decision to explore gesture in the very first rehearsal.

After a single read through of Scene 1, I asked the actors to select one of Michael Chekhov's six archetypal actions that they thought best represented their initial impression of their character. They were invited to make an intuitive choice regarding the action as no character analysis had been done. These actions include 'I give', 'I want', 'I reject', 'I take', 'I hold my ground', and 'I yield'. ${ }^{18}$ This was repeated a few times before different qualities that represented psychological values were introduced. The actors were requested to continue configuring action as gesture with the line(s), while adding the qualities 'lovingly', 'carefully', 'carelessly', 'aggressively', 'excitedly', and so on. Pieces of cloth were introduced to assign tangible expression to the gesture as the actors continued gesturing while reading the scene.

When asked to reflect on the experience, $\mathrm{A}_{3}$ commented: 'Gestures did have an effect, but I cannot explain how. At times I felt I was over-doing it, felt I spoke faster and louder, but when the gesture was removed, it felt more natural and I felt the energy was still there.' Ai stated: 'I felt different shades of the same feeling when repeating the same gesture. I realized I could "give" in different ways and that changed how I felt and how the text sounded.' A2 said: 'I felt the gesture was almost going against what I wanted to do, but it was creating an awareness of what I was doing and saying. I felt I stopped planning how I was going to say something ... because I tend to overthink how I say lines.'

The Setswana cast reported similar experiences. Si noted: 'It helps you just to go and not think what you are saying and how you are saying it, just to go with your intuition.' S2 stated: 'So now you get, OK, so this is how I could react with the text; it made me realize how she thinks.'

These comments potentially speak to the co-expressive nature of gesture and speech. Other comments seem to suggest a sense of ease and comfort with the words and an acknowledgement that the gesture exploration had clarified the characters' thoughts. Based on these comments, it is possible to suggest that the gesture exploration encompassed, to some degree, the systemic process that integrates thinking, being, doing, and interacting (speaking), which echoes Liora Bresler's definition of embodiment. ${ }^{19} \mathrm{How}^{-}$ ever, it is important to observe that the actors were at this point 'reading' the text rather than 'speaking' it, as had been the case in out the first rehearsal.

The actors were engaging with written language - a system of signs and symbols depicted in words that correspond with the world and are, therefore, more prone to cognitive interpretation..$^{20}$ However, connecting the words, although read, meant that they were read with the kinaesthetically activated body, therefore activating intent. Intent is activated from embodied consciousness, as consciousness is inherently kinaesthetic, present in the body that is either moving or is on the verge of moving intentionally. ${ }^{21}$ Therefore, although the actors were engaged in the cognitive act of reading, intent was simultaneously being activated through the moving body, which subsequently affected prosodic delivery and its relationship with words.

Based on my observations and the actors' comments, gesture exploration and the inclusion of tangibles like clothing provided an opportunity for exploring the text in an embodied way, which triggered impulses and the expression of the prosodic elements of speech. Analysis of the actors' use of stress and intonation in Scene 1 revealed that, although the actors in the two casts interpreted the text differently from a prosodic perspective, similar words were given prominence. ${ }^{22}$ These included nouns such as 'life', 'health', and 'earth', and such descriptions as 'complicated', 'kind', 'cleverest', and 'cynical'. Since this text was initially embodied with gesture, it may be noted that physical sensing 
may have had an impact on interpretation, subsequently influencing the choices the actors had made.

Although all the actors delivered prosody according to their uniqueness, there were similarities from a character perspective. Both of the actors who played Masha tended to raise pitch and to lengthen vowels in order to assign meaning. Both actors who played Irina tended to use intensity to convey their intent. Overall, it seems that the Afrikaans cast tended to raise pitch more to emphasize intent, whereas the Setswana cast inserted more words and paralinguistic elements ('mmm', laughing, 'hey'). This potentially indicates the first-language impact on the second-language text and may also be connected to linguistic identity, although several factors may here be at play due to the intricate nature of prosodic expression.

\section{Reflections on Exploring with Drawing and Music in Scene 2}

Scene 2 was read once, followed by a brief analysis and discussion of the context and the transitions for characters from Scene 1. Scene 2 was then divided into two sections, each consisting of four pages of text. The first section was used in exploration by drawing and the second used exploration with music. I decided to split the scene between these two types of exploration so as to allow the actors to focus on a smaller chunk of text in each case. This, I believed, would provide a sense of comfort with the text while it was being explored.

Each cast member received four large sheets of paper and coloured crayons and oil pastels. I invited the actors to sit comfortably in a position that would help them to read the dialogue while drawing. They were then requested to read the dialogue as a group and to draw any lines or shapes while reading. After the first four pages had been explored like this, they were asked to change the lines and shapes that they were drawing, using guidelines such as 'draw circles in different sizes', 'draw any lines, shorter or longer', 'draw small dots', 'draw squares and triangles in different sizes'. I then guided the actors to read the dialogue again, but this time while freely drawing any shapes that could influence how prosodic patterns were embodied. When the drawings were completed, I invited the actors to read or speak the scene while allowing themselves to sense what they had experienced physically, visually, or aurally while drawing.

The actors' ease was noticeable when they reflected on what they had done. A1 stated: 'It took me out of my head, made me forget how I say the lines.' S3: 'In my head it started to break the pattern of how I usually speak.' $S_{1}$ noted: 'For me it was more the text, the importance of the words, the emphasis of the words - it came out so it went into the text.' AI indicated: 'When I look at my picture, I see rhythm, there's like dots and circles, hard stripes and shorter stripe.' These comments suggest a conscious awareness of speech patterns during the drawing exploration.

Cicely Berry used drawing in her work concurrently with speaking lines. ${ }^{23}$ Her approach varies slightly as she asked the actor to draw something specific such as a house. In our case, the actor was simply asked to draw shapes freely. Berry notes that drawing shifts the actor's concentration to something precise, which results in precision being transferred to speech without effort due to the focus being shifted from the words to the physical activity of drawing. ${ }^{24}$ Based on the above comments, it seems that the activity did indeed shift focus from the words. Beyond releasing the burden of over-focus on the words, which is potentially valuable for the second-language actor who may tend to place extra focus on the words rather than let them flow organically, as would be the case for a first-language actor, drawing was employed to assist the actor in examining patterns within the text, a pattern that reflected both the linguistically embedded pattern and the subtext, or the character's emotive pattern. For this reason, the actors were requested to draw lines and shapes that were not representative of anything.

Prosody is essentially a sound-pattern assigned to language to generate meaning; shaping of sounds into patterns is an innate human expression that presents intent and precedes language. ${ }^{25}$ This refers to 'the 
manner in which something is said' rather than 'what is being said', implying that the overall acoustic pattern of an utterance conveys meaning at a paralinguistic level. ${ }^{26}$ The term 'pattern' recurs in the actors' description of their experience of drawing while speaking. Their exploration allowed the actors to discover the acoustic pattern(s) of the text in their own embodied manner through the physical act of drawing; and this enabled them to find speech chunks that needed to be highlighted, as happens in connected speech to generate meaning and to express the character's thoughts and intent within the scene. ${ }^{27}$ The exploration also has a tangible outcome - a visual image to which the actor can refer to recreate the patterns explored. The image indicated belongs to the final drawings produced during the exploration (Figure 1 ).

The first figure is from the final drawings of the Afrikaans and Setswana actors who played Olga. It is interesting to note that, although this exploration was done on different days with each cast, without contact between them, both of the actors chose independently to draw only in red only, and both produced a somewhat erratic pattern consisting of curved lines and circular shapes, with limited strong edges. There is also evidence of forceful scratching movements. One could speculate that a possible undercurrent of frustration with her text resulted in the choice of colour, as well as the scratching. Yet, at the same time, each controls her prosodic patterns to have control and maintain politeness.

The final explorative drawings of the two actors who played Masha have their own expressive quality (Figure 2). It is interesting to note the combination of grid-like blocks and circular shapes in each case. Each may be a result of the complexity of the character's subtext, which spans various emotional intents. The combination of round with strong angular shapes is evident in the speech patterns that are described later on. Perhaps the varying shapes comment on the character, on the complexity and turbulence of her inner life, as described by one of the actors who played Masha: 'So with the way I drew, not even paying attention, the lines they are straight, they have a direction in which they are going,

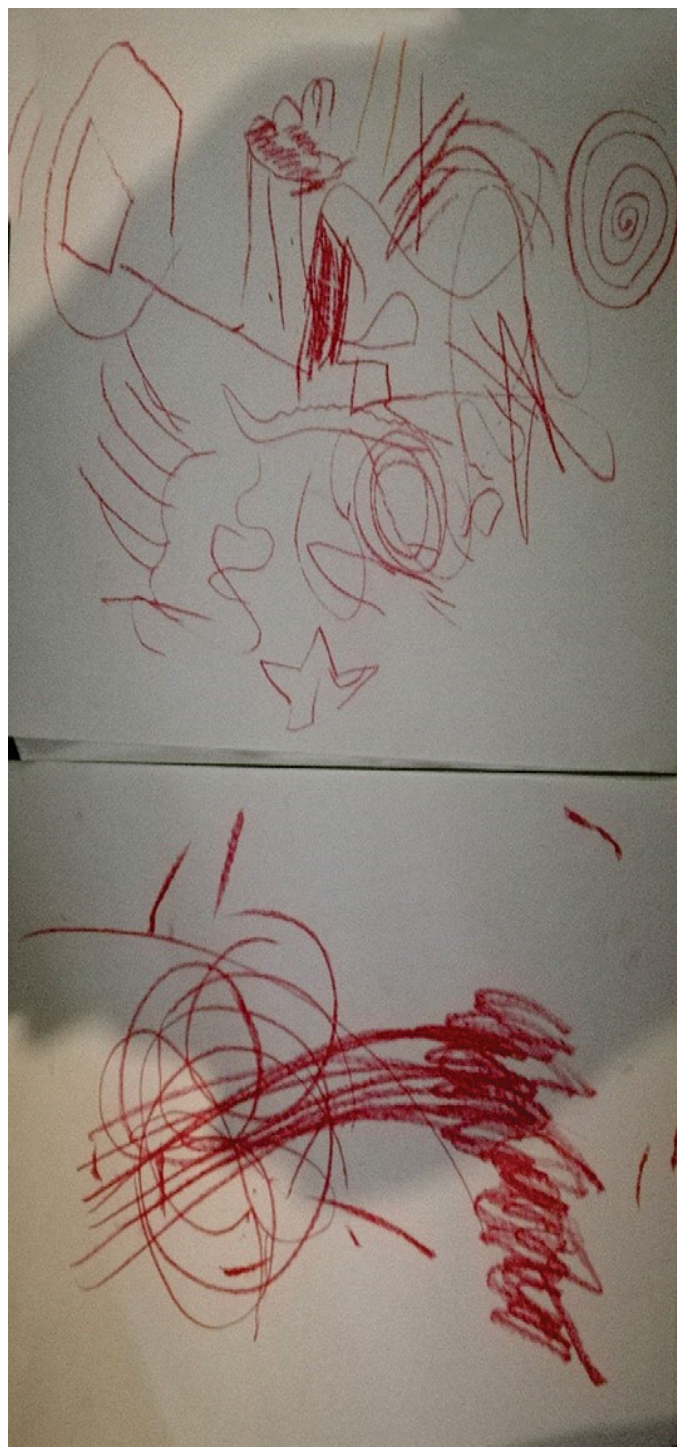

Figure 1. Drawings by the actors playing Olga. Photo by the author.

but at the same time she doesn't have a direction in her life, it is complete turmoil, but it is organized chaos.'

Lastly, there are the final drawings of the two actors who played Irina, both of whom selected a combination of short lines, blocks and circles or curvy lines in more than one colour (Figure 3). These are referred to when the acoustic pattern is discussed below. What these also have in common is the drawing of smaller shapes that fill the entire surface. One could speculate on the meanings of these 


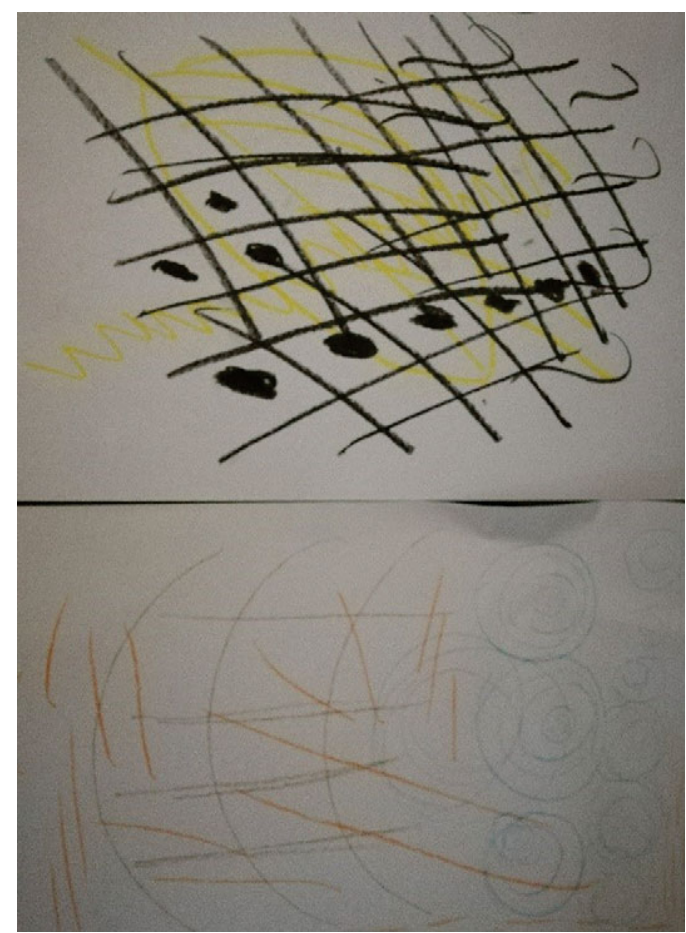

Figure 2. Drawings by the actors playing Masha. Photo by the author.

drawings, but, ultimately, they are simply outcomes of an exploration. What is potentially worth noting, however, is the fact that, although the actors are from different cultural and linguistic backgrounds, each personally unique and drawing on different days, their drawings have common elements.

Since the words in the text and the characters' subtext were the only factors they had in common, the pattern in the words, both linguistic and paralinguistic, was translated visually. It is also potentially valuable to surmise that each actor's visual image symbolizes the acoustic and emotional pattern of the text in a very personal way. Emotions can be viewed as mental images generated by our sensory patterns; ${ }^{28}$ and this suggests that a visual image can assist an actor to generate a physical and vocal pattern for conveying a character's intent in a second-language text.

The use of music in the second portion of Scene 2 was meant to assist the actors to discover emotional patterns in the text rather than simply in the words. Prosodic



Figure 3. Drawings by the actors playing Irina. Photo by the author.

conveyance of emotion does not require language content, unlike the conveyance of attitude, which is synonymous with language content. ${ }^{29}$ In other words, the prosodic expression of emotion does not require the use of words. A sound pattern, which may be equated to music, portrays feeling. Here music was chosen that might echo the melancholy present in the text - piano compositions by South African composer Franco Prinsloo, with his full consent. Short tracks that clearly provided shifts in tempo, rhythm and melody were selected.

The actors were asked to find a space and to allow the music to influence how they moved in it. As soon as they were at ease, they were requested to read the final four pages of Scene 2 over the music. In their immediate reflection following the exploration, A2 states: 'The music took me to a whole different place, it stirred something, made me think of all her sadness, how trapped she is. It gave me a sense of nostalgia, thought of her parents, saw them ...' S2 noted how 'the music brought the emotive aspect of how we could 
be feeling at that particular time', while $\mathrm{S}_{1}$ said that 'the music helped bring out my character, how she reacts to her sisters and what they are saying'. One could argue that the addition of music echoes in some way the pre-linguistic intuitive sound-pattern mediating intent. Music shifted the second-language actors' awareness away from the language (word-pattern) towards the music (soundpattern) to access an intuitive response that enables feeling and activates imagination.

\section{Reflections on Exploring Phonemes in Scene 3}

Whereas the previous two sessions explored embodied activities in order to influence the prosody of delivery, this session dealt with a more linguistic approach because it directly explored phonemes and words, and so speech. The initial exploration was connected to the previous session as the actors read the first pages of the scene over the music that had previously been used. While this was being explored, I subtly removed the music and invited the cast to become aware of the body in space and in relation to other actors. I provided verbal suggestions to make the actors aware of the shapes the body created in relationship to these actors as well as the architecture, drawing on elements of Anne Bogart's 'Viewpoints' of time and space. ${ }^{30}$ The Viewpoints become points of awareness of the elements that the performer relies on while working: time; tempo (duration, repetition, and kinaesthetic response); and space (shape, gesture, architecture, special relationship, and topography). ${ }^{31}$

The actors were then requested to focus on one or two lines of their choice from the scene without reference to their text. They were requested to repeat these lines while sensing the body floating upward, followed by repeating the lines with a sense that their body was grounded, sinking into the floor. This could be equated to the assertion of strength and lightness in the body-mind experiences, or as described by Rudolph Laban: a way of actively engaging with the gravitational pull and overcoming, which leads to sensing weight. $^{32}$ The cast continued repeating the lines, and, this time, I guided them to senses of the body shrinking and growing. As a result, the actors sensed the qualities of shape that Laban calls 'spreading', 'enclosing', 'advancing', and 'retreating', although these specific terms were not used during the exploration. ${ }^{33}$

The actors were then asked to contain their inner awareness, thus not making it visible in the outer body while they spoke the text. The entire scene was read, and they were asked to vary their focus between exploring physical awareness, suggested by the Laban shape qualities, and 'playing' the vowels and consonants in the text. Guided instructions included the play of sustaining or lengthening vowels and consonants, and play with pitch to see what happened when vowels and consonants in the line were taken up or down. Finally, the actors read the scene, and I asked them simply to employ any elements of the awareness that they had established during the exploration. A3 commented: 'I realized that, as my body changed, my speech changed but it was subconscious, not like the gestures where I consciously did something.' Similarly, A2 noted: 'I was speaking the words and my body changed, and when my body changed, the meaning changed, and it sounded and felt different.' $S_{3}$ said, 'It helped me to just go and not worry about the words,' while Si reported: 'For me, it was the most exciting thing, it gave texture.'

The actors were tasked with consciously exploring phonemes, when intent is conveyed, since they are normally absorbed in the prosodic pattern. ${ }^{34}$ This conscious focus on segments does not mirror spontaneous speech, and it may explain why some actors initially found the deliberate focus on phonemes challenging. However, when these segments (phonemes) were produced differently (adjusted in pitch, duration, and intensity), this influenced the pattern, which altered the intent. It could be that these were the pattern adjustments on which the actors commented above. Thus the actors sensed the vowels and consonants as expressive without focusing on correctness, which is a tendency of secondlanguage speakers. ${ }^{35}$ Exploration of the pitch and intensity of the phonemes influenced the 
pattern in terms of how the phonemes were sensed, resulting in increased precision or laxness to mirror the emotion being conveyed through the prosody. ${ }^{36}$

Working in this way may have initiated a feeling of prosodic patterns associated with the expression of primary emotions, which altered the delivery of the text. If so, then the exploration promoted what may be termed an organic interrelationship between the body, voice, emotion, perception, senses, and thinking. The actors' comments suggest that this was sensed, allowing them to experience the expressiveness and intrinsic musicality of phonemes, which generated an embodied pattern that activated a recognizable emotive pattern; ${ }^{37}$ and this, instead of a search for correctness, seemed to have assisted the second-language actors to find intent in the English text.

\section{Reflections on Exploring Words in Scene 4}

The final exploration escalated from using phonemes to what may be termed paralinguistic signals such as laughing, sighing, and so on, ultimately to investigate words consciously. ${ }^{38}$ The session was initiated by the actors, who were tasked with reading the scene and inserting a voiced filler or filled pause such as 'um' or ' $\mathrm{mmm}$ ' before or after each line. ${ }^{39}$ This was repeated with a paralinguistic signal such as an expressive sound ' $a h^{\prime}$, for example, or a sigh. The actors were then asked to select any of these insertions so as to see what had varied between them. After this was established, I asked the actors to stop inserting the signal verbally but to sustain the feeling that they had caught or continue to 'think' it. The exercise was followed by insertions of different words, which encompassed affirmation, negation ('yes' or 'no'), linking words ('well'), question words ('how?'), and expressive words.

Gradually I guided the actors to insert a word or phrase in their first language. The scene was read like this a number of times, varying the insertion every time. Finally, I asked the actors to remove the insertions but sustain what they had sensed when they had made the insertions. The actors also reported a constructive experience. A1 stated: 'The filler felt natural and gave a sense of drive to my text, [it] felt good in terms of how she thinks and speaks.' A3 said: 'It was really cool and made the dialogue feel more natural. For me, specifically, just using the sound before the line - it felt so natural.' S2 noted: 'The different words made it lighter, it felt more natural to me.' Si said: 'Naturally I don't use so much of the strong words as a person, so using them it changed the way I spoke.'

Prosody conveys the intent of the speaker and information about the utterance itself. ${ }^{40}$ Used in a conversation, 'social ritual' results in certain utterances being dispensed as habitual, thus assigning specific prosodic features to how the utterance is uttered. ${ }^{41}$ For example, the word 'really' could habitually be expressed with a lift in pitch in the final syllable to signal questioning. Allowing these familiar patterns to influence the text altered the prosodic delivery and emphasized specific intent. For example, when 'no' was inserted, the pitch emphasis was dropped, which caused the line of text that followed also to be produced with a downward pattern, assigning prominence to specific words that mirrored the negative notion of 'no'. The actors used descriptors such as 'natural' and 'different impulses' in their commentaries, possibly suggesting that a given insertion enabled an interpretation that varied from their initial interpretation. So the word inserted guided the interpretation. Even so, exploration drew on the familiar or, as Arthur Lessac suggests, on a familiar event, to have actions that flow from the body's natural response and are performed with ease. ${ }^{42}$ Although different patterns and impulses were generated, the flow was based on the familiar, which reduced effort and possibly provided a sense of the 'natural'.

The actors also recorded positive experience when code switches were inserted first-language insertions that spanned across the words or short phrases into the secondlanguage text. A3 stated: 'It was natural, it was very playful. I almost felt that a different side of the character emerged.' S2 indicated: 'The vernacular word gave me a sense of sarcasm, 
I could feel the character.' S3 said: 'It helped me to just flow, to go with my instinct . . . it really gave me a connection with my sisters.' A4 commented: 'It felt natural, it was automatic. It felt more real, it was goose bumps connected.'

Language is a marker of identity and thus the first language is connected to the sense of 'self' and may have an 'emotional significance'. ${ }^{43}$ Inserting first-language utterances connects the actor to the embodied self, which aids the meaning-making of the text. This was echoed in the actors' feedback, where descriptors such as 'connection', 'natural', and 'nakedness' were used to describe their experience of text and subsequently character(s) when first-language utterances were used. In the South African context, code switching is deemed normal and a means of retaining linguistic identity. ${ }^{44}$ It may be that, for the actors, this practice was natural and so it enabled them to connect with the text on a deeper level than merely delivering the text in English. Inserting utterances from vernacular languages into English has become a linguistic norm and a manner of reflecting membership of different groups, expressing emotion and humour. ${ }^{45}$

This experience is reflected in the actors' responses in such descriptors as 'light', 'playful', 'a comical element', 'felt sarcastic', 'different side of the character', and 'connection with my sisters'. Such comments suggest that the insertion of first-language codes established a stronger connection between the actors' expressive self and the text as each line had sensed intent, which had an impact on the prosodic delivery of that text. The nature of the inserted second-language utterances inserted also affected the prosodic delivery. In contrast to gesture exploration, there was a significant difference between the casts in which words were emphasized, resulting in different interpretations. This may have been caused by the 'code switches' inserted, which affected how prominence was assigned.

\section{Post-Production Reflections}

The explorations were built upon and integrated into the rehearsal process that followed, in which the two casts worked together. Directorially, the explorations directly informed the staging. Individual discussions were conducted with each actor after performances. They were asked to reflect on the experience as a whole. The first discussion was conducted a week after the first performance, and the final discussion three weeks after the performance. Conversation was unstructured to enable spontaneous reflection, free from prompting. These conversations revealed that the actors found the explorative process constructive for dealing with the English text. A3 observed: 'The explorations were so fruitful. It stuck with me, it made me understand the essence of the character without having to analyze every word. I made it more instinctive.' S2 said: 'I feel like all these characters, they just came about - you didn't have to say "OK, let me find something in my memory to link with" - it just came by itself.' A3 said:

Explorations and specifically bringing the body in when dealing with the text gave me a sense of comfort, to go over the top, and then pull back, then it felt like speaking with the whole body. The intensity was there, the body was there, the words were almost a secondary thing, it just came, which was very interesting. I liked it.

\section{Overall Reflections}

The experimental process set out to assist the second-language actor with embodying and voicing a text in English text through explorations that aimed to activate a creative use of the prosodic elements of speech. The secondlanguage actors reported a sense of ease when dealing with the text, which is significant, given the aims of this process which included not inhibiting intent by a secondlanguage text. Although they did not mention prosody directly, they noted that the process assisted them to discover the character(s) through the text. This could be the actor's primary goal - to be truthful in imaginary circumstances by embodying the playwright's words to convey the character's thoughts and feelings to the audience. Based on the actors' comments, it seems that they emphasized the importance and relevance of 
the text as an ultimate source for creative expression.

The actor's creative individuality should be honed by training the actor's three basic expressive tools: body, voice, and imagination. ${ }^{46}$ The process followed in this experiment enabled such individuals' creativity by activating imagination, body, and voice. Based on the actors' reflections, it is clear they were stimulated to discover prosodic options in an embodied fashion, which enabled them to experience the text rather than analyze it. Going by the actors' reflective comments, it seems that the explorations of prosodic elements of speech generated an embodied awareness, a connection with text, and the character's circumstances embedded in it; and these helped the actors to be in touch with what they had experienced, to be actively engaged with the ensemble as a whole, and to translate their experiences to the audience.

The actors are trained professionals, but what is important is that they expressed their experiences through a second-language text. It was the goal of this process to use such a text as a base for prosody as an intuitive embodied activity from its very first engagement with the words. Prosody was not applied theoretically or cognitively, but drew on a pre-linguistic intuitive level, which is innate and so universal in humans. In the multilingual context of South Africa, second-language actors are confronted with the prosodic elements of speech when they need both to interpret and to embody text for performance. The strategy applied here turns that around by starting with the body and unconsciously allowing prosodic expression to emerge from the body. This is then developed to explore phonemes and words as part of an integrated approach, culminating in the embodied experience of text as part of meaning-making.

A sequence emerges when I look back on how we worked. The explorations developed as they went from embodiment (gesture) to consciousness (phonemes and words) towards establishing embodied consciousness. This was an interconnected journey, so to speak, that initiated with physically selfgenerated impulses, or awareness, ${ }^{47}$ and concluded with mindfully moving between observation and immersion while staying anchored in the body. ${ }^{48}$ This does not imply that all cognitive analysis of text is negative, for it remains essential that the actor achieve a firm understanding of the playwright's intentions. However, engaging the body and the voice in the very discovery of the text potentially accelerates body-mind connectivity in how the text is understood and communicated. This is arguably particularly relevant for the second-language actor in that it stimulates an active sense of text as a physical experience instead of a cognitive translation; and this, the actors had noted, activated the imagination. Michael Chekhov observed that the actor should use the imagination in an effort to develop 'instinct' which, rather than logic, gives responses that are 'truthful'. ${ }^{49}$ What is at issue is the interplay between physical, emotional, and mental capacities.

What we explored shaped our performances. We retained the fabrics we had used and made our experimental hanging and packing clothes an integral part of the set (Figures 4 and 5). Some of the music tracks were turned into transitions between scenes and elements. First-language insertions were retained. This truly situated the piece and its themes in the multilingual South African context.

Examining prosody from an acting and performance perspective throughout this experiment reaffirmed that it is truly a marker of uniqueness because it is influenced by variables such as language, culture, personality, attitude, situation - the variables are multiple. It was necessary, therefore, to work with a strategy that honoured uniqueness rather than assigned principles based on perceptions of 'correctness'. Chris Banfield states that acting is complex due to the varied performance traditions present in different cultures. ${ }^{50}$ Yet concurrently, prosody involves elements that are universal, like the patterns that depict primary emotions. In our experiment, we connected embodied explorations to a text-based theatre tradition while allowing the actor to infuse what they were doing with their personal uniqueness and linguistic identity. We created an interplay of sorts between the 




Figure 4. The actors packing clothes, in performance at the POPArt Theatre, Johannesburg. Photo: Thapelo Sebogodi.

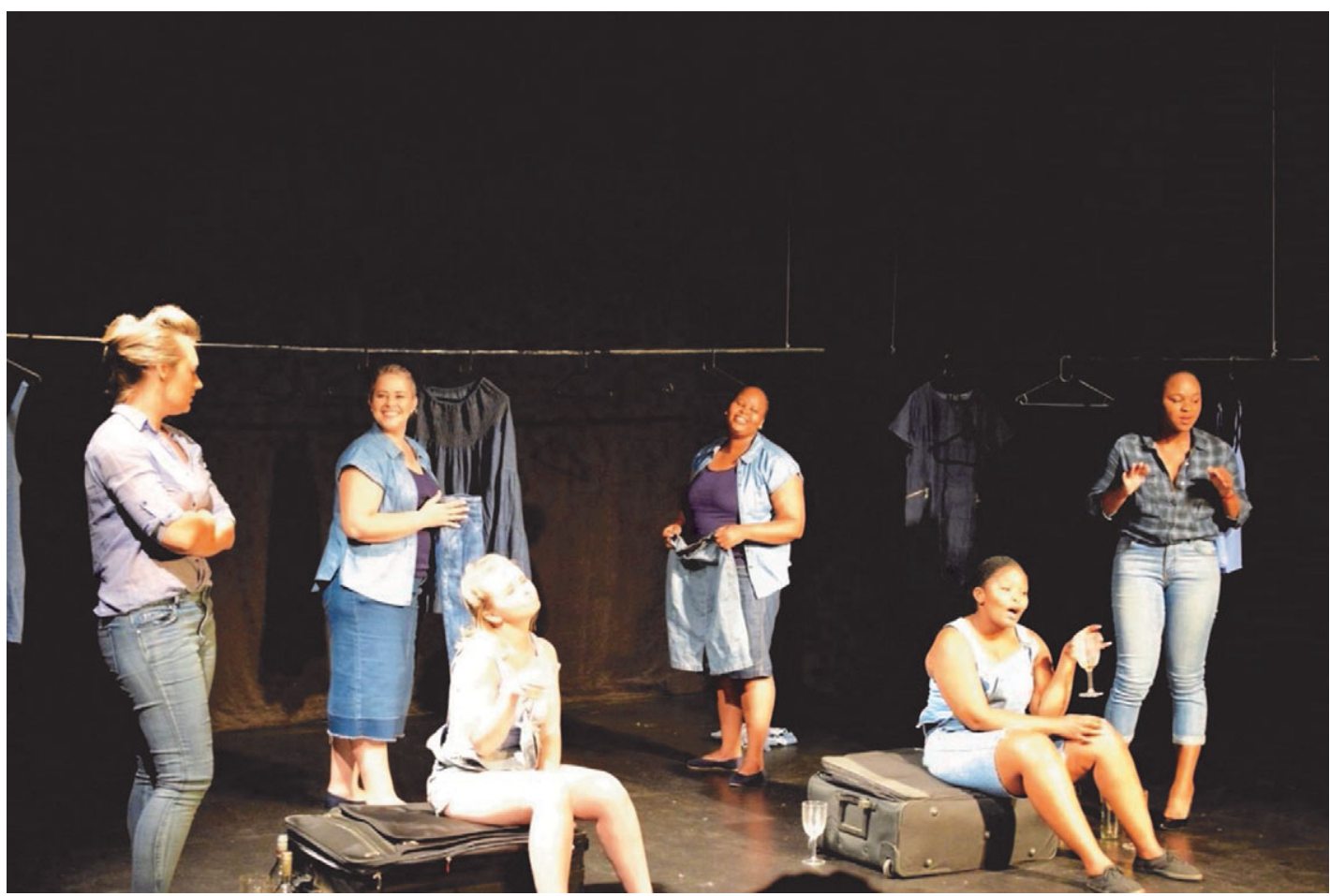

Figure 5. The full cast in performance at the POPArt Theatre, Johannesburg. Photo: Thapelo Sebogodi. 
universal patterns that denote emotion and the language-specific patterns that reflect linguistic identity in a framework that enabled the second-language actor to convey intent to our multilingual audience.

\section{Notes and References}

1. Marisa Keuris, 'The (Re)Working of Dramatic Language in Janet Suzman's The Free State', Journal of Literary Studies, XXIII, No. 1 (2007), p. 1-15 (p. 2).

2. Mark Axelrod, The Poetics of Stagecraft and Dialogue in Chekhov's The Cherry Orchard, in Axelrod, Poetics of Prose (London: Palgrave Macmillan, 2016), p. 45.

3. Richard Hornby, 'Playing Chekhov', Hudson Review, LXI, No. 1 (Spring 2009), p. 113-19 (p. 113).

4. Janine Lewis, 'Physical Actions as Expressive Performance Narratives: A Self-Reflexive Journey', South African Theatre Journal, XXIV, No. 1 (2010), p. 175-200 (p. 175).

5. Satoshi Imaizumi, Koichi Mori, Shigeru Kiritani, Hiroshi Hosoi, and Mitsuo Tonoike, 'Task-Dependent Laterality for Cue Decoding during Spoken Language Processing', Neuroreport, IX, No. 5 (1998), p. 899-903 (p. 901).

6. Pavel Trofimovich and Wendy Baker, 'Learning Second Language Suprasegmentals: Effect of Second Language Experience on Prosody and Fluency Characteristics of Second Language Speech', Studies in Second Language Acquisition, XXVIII, No.1 (2006), p. 1-30 (p. 23).

7. The cast members are reflective of many South Africans who use multiple languages, in this case Sesotho and Setswana. The two languages are members of the Sotho-Tswana language family and are closely related.

8. Regarding social ritual, see Gerald Knowles, Patterns of Spoken English: An Introduction to English Phonetics (London: Routledge, 2014), p. 207; for paralinguistic and non-verbal expression, see Alan Cruttenden, Intonation (Cambridge: Cambridge University Press, 1997), p. 177; on age, see Sue Peppé, Jane Maxim, and Bill Wells, 'Prosodic Variation in Southern British English', Language and Speech, XLIV, No. 3 (2000), p. 309-34; on gender, see Marc D. Pell and Laura Monetta, 'How Parkinson's Disease Affects Non-Verbal Communication and Language Processing', Language and Linguistics Compass, II, No. 5 (September 2008), p. 739-59; on culture, see Marc D. Pell, 'Reduced Sensitivity to Prosodic Attitudes in Adults with Focal Right Hemisphere Brain Damage', Brain and Language, CI, No. 1 (2007), p. 64-79; on power, see Wolff-Michael Roth and Kenneth Tobin, 'Solidarity and Conflict: Aligned and Misaligned Prosody as a Transactional Resource in Intra- and Intercultural Communication Involving Power Differences', Cultural Studies of Science Education, V, No. 4 (2010), p. 807-47; and for affective or emotive expression, see Janet B. Pierrehumbert, 'Phonetic Diversity, Statistical Learning, and Acquisition of Phonology', Language and Speech, XLVI, Nos. 2-3 (2003), p. 115-54.

9. The adaptation was also limited to four shorter scenes for practical purposes as the participants' availability was limited due to other commitments.

10. Barnaby B. Barratt, The Emergence of Somatic Psychology and Bodymind Therapy (London: Palgrave Macmillan, 2010), p. 7 .
11. David Krasner, An Actor's Craft: The Art and Technique of Acting (London: Palgrave Macmillan, 2012), p. 36-7.

12. Peter Roach, 'On the Distinction Between "StressTimed" and "Syllable-Timed" Languages', in David Crystal, ed., Linguistic Controversies (London: Arnold, 1982), p. 73-9 (p. 73).

13. The Afrikaans Li cast included a fourth member, as one of the participants had to leave the project at the end of Phase 2. She was replaced by the new participant, A4, who was taken through the explorations conducted in Phase 1 and 2 before joining the cast for the final rehearsal stage.

14. Núria Esteve-Gibert and Pilar Prieto, 'Prosodic Structure Shapes the Temporal Realization of Intonation and Manual Gesture Movements', Journal of Speech, Language, and Hearing Research, LVI, No. 3 (2013), p. 850-64 (p. 861).

15. David McNeill, How Language Began: Gesture and Speech in Human Evolution (Cambridge: Cambridge University Press, 2012), p. 90.

16. Phillip B. Zarrilli, Psychophysical Acting: An Intercultural Approach After Stanislavski (London: Routledge, 2009), p. 19.

17. Rick Kemp, Embodied Acting: What Neuroscience Tells Us About Performance (London: Routledge, 2012), p. 3.

18. Lenard Petit, The Michael Chekhov Handbook: For the Actor (London: Routledge, 2010), p. 66.

19. Liora Bresler, ed., Knowing Bodies, Moving Minds: Towards Embodied Teaching and Learning (Dordrecht: Kluwer Academic Publishers, 2004), p. 7.

20. Rena Cook, 'Verbal Arts Workbook: A Practical Course for Speaking Text by David Carey and Rebecca Clark Carey', Voice and Speech Review, VII, No. 1 (2011), p. 355-6.

21. Robert Hanna and Michelle Maiese, Embodied Minds in Action (Oxford: Oxford University Press, 2009), p. 87 .

22. Ann K. Wennerstrom, The Music of Everyday Speech: Prosody and Discourse Analysis (Oxford: Oxford University Press, 2001), p. 46.

23. Cicely Berry, The Text in Action: A Definitive Guide to Exploring Text in Rehearsal for Actors and Directors (London: Virgin Books, 2001), p. 220.

24. Cicely Berry, The Actor and the Text (London: Virgin Books, 1987). p. 189.

25. Richard Luchsinger and Godfrey Arnold, VoiceSpeech-Language: Clinical Communicology: Its Physiology and Pathology (California: Wadsworth, 1965), p. 405.

26. Knowles, Patterns of Spoken English, p. 209.

27. Ibid., p. 210.

28. Nicola Shaughnessy, 'Imagining Otherwise: Autism, Neuroaesthetics, and Contemporary Performance', Interdisciplinary Science Reviews, XXXVIII, No. 4 (2013), p. 321-34.

29. Pell, 'Reduced Sensitivity', p. 66.

30. Anne Bogart and Tina Landau, The Viewpoints Book: A Practical Guide to Viewpoints and Composition (New York: Theatre Communications Group, 2011), p. 9-10.

31. Ibid., p. 11.

32. Peggy Hackney, Making Connections, Total Body Integration through Bartenieff Fundamentals (New York: Routledge, 2002), p. 41.

33. Ibid., p. 222.

34. Andrew M. C. Kimbrough, 'The Sound of Meaning: Theories of Voice in Twentieth-Century Thought and Performance' (unpublished PhD thesis, Louisiana State University, 2002), p. 107 
35. Alan Juffs, 'Tone, Syllable Structure and Interlanguage Phonology: Chinese Learners' Stress Errors', International Review of Applied Linguistics in Language Teaching, XXVIII, No. 2 (1990), p. 99-118 (p. 111-12).

36. Rocco Dal Vera, 'The Voice in Heightened Affective States', in Dal Vera, The Voice in Violence: And Other Contemporary Issues in Professional Voice and Speech Training (New York: Applause, 2001), p. 63-4; and Iain R. Murray and John L. Arnott, 'Applying an Analysis of Acted Vocal Emotions to Improve the Simulation of Synthetic Speech', Computer Speech and Language, XXII, No. 2 (2008), p. 107-29 (p. 108).

37. Kristin Linklater, Freeing Shakespeare's Voice: The Actor's Guide to Talking the Text (New York: Theatre Communications Group, 1992), p. 13; Arthur Lessac, The Use and Training of the Human Voice (California: Mayfield, 1997), p. 74.

38. Knowles, Patterns of Spoken English, p. 207.

39. William R. Tiffany and James A. Carrel, Phonetics: Theory and Application (New York: McGraw-Hill, 1977), p. 161.

40. Kiwako Ito and Shari R. Speer, 'SemanticallyIndependent but Contextually-Dependent Interpretation of Contrastive Accent', in Sónia Frota, Gorka Elordieta, and Pilar Prieto, eds., Prosodic Categories: Production, Perception and Comprehension (Dordrecht: Springer, 2011), p. 70 .
41. Knowles, Patterns of Spoken English, p. 193.

42. Erica Tobolski and Deborah Kinghorn, 'Finding Common Ground: Lessac Training Across Cultures', Theatre Symposium, XXV, No. 1 (2017), p. 93-107 (p. 93).

43. Rusi Jaspal, 'Language and Social Identity: A Psychosocial Approach', Psych-Talk, LXIV (2009), p. 17-20 (p. 17).

44. Ibid., p. 18.

45. David Gough, 'Black English in South Africa', in Vivian de Klerk, ed., Focus on South Africa (Amsterdam: John Benjamins Publishing Company, 1996), p. 53-78.

46. David Zinder, Body Voice Imagination: ImageWork Training and the Chekhov Technique (New York: Routledge, 2013), p. 3 .

47. Antonio Damasio, SelfComes to Mind: Constructing the Conscious Brain (London: William Heinemann, 2010), p. 192.

48. Roz Carroll, 'In Search of a Vocabulary of Embodiment', Body, Movement, and Dance in Psychotherapy, VI, No. 3 (2011), p. 245-57 (p. 255).

49. Michael Chekhov, On the Technique of Acting (New York: Harper Collins, 1991), p. 6.

50. Chris Banfield, 'Acting With Both Sides of Your Brain? Considering the Consequences of Adopting More Rigorous Psychological Languages in Acting Research', Research in Drama Education, V, No. 2 (2000), p. 235-47 (p. 240-1). 